\title{
Duration of the unconditioned stimulus in appetitive conditioning of honeybees differentially impacts learning, long-term memory strength, and the underlying protein synthesis
}

\author{
Kathrin Marter, M. Katharina Grauel, Carmen Lewa, Laura Morgenstern, \\ Christina Buckemüller, Karin Heufelder, Marion Ganz, and Dorothea Eisenhardt \\ Freie Universität Berlin, FB Biologie, Chemie, Pharmazie, Institut für Biologie, Neurobiologie, 14195 Berlin, Germany
}

\begin{abstract}
This study examines the role of stimulus duration in learning and memory formation of honeybees (Apis mellifera). In classical appetitive conditioning honeybees learn the association between an initially neutral, conditioned stimulus (CS) and the occurrence of a meaningful stimulus, the unconditioned stimulus (US). Thereby the CS becomes a predictor for the US eliciting a conditioned response (CR). Here we study the role of US duration in classical conditioning by examining honeybees conditioned with different US durations. We quantify the CR during acquisition, memory retention, and extinction of the early long-term memory (eLTM), and examine the molecular mechanisms of eLTM by interfering with protein synthesis. We find that the US duration affects neither the probability nor the strength of the CR during acquisition, eLTM retention, and extinction $24 \mathrm{~h}$ after conditioning. However, we find that the resistance to extinction $24 \mathrm{~h}$ after conditioning is susceptible to protein synthesis inhibition depending on the US duration. We conclude that the US duration does not affect the predictability of the US but modulates the protein synthesis underlying the eLTM's strength. Thus, the US duration differentially impacts learning, eLTM strength, and its underlying protein synthesis.
\end{abstract}

Animals adapt their behavior to ongoing changes in their environment, such as the occurrence of dangerous situations or changes in the profitability of food sources. Learning environmental stimuli as predictors for these meaningful situations enables animals to respond to danger or reward appropriately and in a timely manner. Learning the association between an environmental stimulus that initially has no meaning for the animal and a meaningful, rewarding or punishing stimulus resembles classical Pavlovian conditioning in which an animal learns that a neutral conditioned stimulus (CS) predicts the occurrence of a meaningful unconditioned stimulus (US) eliciting a conditioned response (CR). The extent to which the CS predicts the occurrence of the US depends on how often the animal previously experienced the association between these two stimuli, that is, on the number of conditioning trials (Rescorla and Wagner 1972; Schultz et al. 1997). Moreover, the number of conditioning trials is crucial for the stability of a memory formed upon classical conditioning as well as for the molecular mechanisms underlying the formation of this memory: After one CS-US trial, short-lasting memories are formed that are based on transient protein modifications such as phosphorylation, whereas after multiple CS-US pairings a stable long-term memory is formed that undergoes a protein synthesis-dependent process of stabilization (Tully et al. 1994; Friedrich et al. 2004; Davis 2011). Thus, both the predictability of the US-which is mirrored in the CR-and the mechanisms of memory formation depend on the number of conditioning trials.

In recent years the idea has emerged, based mainly on findings from operant conditioning in vertebrates, that multiple features of a reward, such as sensory, hedonic, motivational, emo-

\section{Corresponding author: dorothea.eisenhardt@fu-berlin.de} Article is online at http://www.learnmem.org/cgi/doi/10.1101/lm.035600.114. tional, and temporal elements, are associated with the CS (Delamater and Oakeshott 2007; Smith et al. 2011; Berridge 2012; Delamater 2012).

Thus, it seems likely that in classical conditioning the predictability of a US depends not only on the number of trials but also on certain features of the US, and, accordingly, that memory formation is affected by these US features.

We here test the hypothesis that, analogous to the number of conditioning trials, the US' features affect both the predictability of the US and the mechanisms of memory formation. In order to test this hypothesis we here examine the role of the duration of the US in learning and memory formation in an invertebrate model system, the honeybee, Apis mellifera. Honeybees have a pronounced ability to learn about food rewards that is rooted in the necessity for efficient foraging of nectar and pollen to guarantee reproduction, and survival of their colonies (Opfinger 1931; Von Frisch 1967; Menzel 1990, 1999; Seeley 1995). Accordingly, certain reward features have been demonstrated to play a role in reward learning in free-flying honeybees (Menzel et al. 1993; Bitterman 1996; Gil et al. 2007, 2008, 2009; Gil and De Marco 2009; Gil 2010).

Following classical olfactory conditioning where an odor, the CS, is paired with a sucrose stimulus, the US, honeybees form memories of different stability, short-term memories (STM), midterm memories (MTM), and long-term memories (LTM) depending on the number of CS-US trials applied during conditioning (Menzel 2001). Two LTMs are distinguished based on the

\footnotetext{
C 2014 Marter et al. This article is distributed exclusively by Cold Spring Harbor Laboratory Press for the first 12 months after the full-issue publication date (see http://learnmem.cshlp.org/site/misc/terms.xhtml). After 12 months, it is available under a Creative Commons License (Attribution-NonCommercial 4.0 International), as described at http://creativecommons.org/ licenses/by-nc/4.0/.
} 
molecular mechanisms of memory formation and the time-point of retention: Early LTM (eLTM) can be retrieved 1 and 2 d, late LTM (ILTM) 3 and $4 \mathrm{~d}$ following conditioning. The formation of eLTM depends on translation whereas the formation of ILTM depends on translation and transcription (Wustenberg et al. 1998; Friedrich et al. 2004; Matsumoto et al. 2014).

In free-flying honeybees a role of the reward duration in reward learning has been demonstrated (Menzel 1968). Moreover, in a previous study in harnessed honeybees we demonstrated that the duration of a US presented during classical conditioning is critical for the formation of extinction memories following extinction of eLTM. This finding suggests that the duration of the sucrose stimulus impacts eLTM formation such that extinction memory formation is affected (Stollhoff and Eisenhardt 2009). Accordingly, we became interested in the role of US duration in eLTM formation and in this study elucidate the role of the US duration in classical conditioning. We quantify the conditioned response (CR) during acquisition, memory retention, and extinction, and study the molecular mechanisms of eLTM formation by interfering with protein synthesis. We find that the US duration affects neither the probability nor the strength of the CR during acquisition and eLTM retention. Thus we conclude that the predictability of the US by the CS is not dependent on the US duration. We find that varying the US duration alters the susceptibility of resistance to extinction to protein synthesis inhibition. This finding indicates that the eLTM's strength depends on protein synthesis in a US-dependent manner.

\section{Results}

\section{US duration does not influence the $\mathrm{CR}$ during acquisition}

First, we examined whether the US duration impacts the predictability of the US by the CS during classical conditioning. The CR toward the CS indicates that the CS induces a prediction about the US (Schultz et al. 1997). Accordingly, we examined whether the US duration impacts the CR during acquisition in olfactory conditioning of the proboscis extension response (PER). We, and other groups, found that the US duration does not impact the occurrence of the CR during acquisition (Stollhoff and Eisenhardt 2009; Shafir and Yehonatan 2014). Thus, we hypothesize that the dichotomous behavioral data recorded in these studies are not adequate measures for the CR. Accordingly, in the present study we quantified the CR by measuring the quantifiable response of muscle 17 (M17) (Snodgrass 1956), a muscle involved in proboscis extension (Rehder 1987; Smith and Menzel 1989a,b). Four groups of honeybees were conditioned with three CS-US pairings with an intertrial interval (ITI) of $10 \mathrm{~min}$ (Fig. 1A). The groups differed in the duration of the
US presentation during acquisition. The US was presented for 2 , 4,6 , or $10 \mathrm{sec}$.

We first analyzed the occurrence of the CR during acquisition. The percentage of animals responding with a CR increased during conditioning. Bees increased their responses in the course of acquisition from $0 \%$ in the first acquisition trial to $65.66 \%-$ $73.20 \%$ in the third trial. This increase was significant (repeatedmeasures ANOVA: trial effect $F_{(1,405)}=165.4, P<0.001$ ). No difference in the percentage of animals responding with a CR was observed between groups (group effect $F_{(3,405)}=0.18, P=0.913$, group $\times$ trial interaction $\left.F_{(3,405)}=0.75, P=0.526\right)$ (Fig. 1B). Thus, we reproduced our finding from a previous study (Stollhoff and Eisenhardt 2009) that the probability of the CR during acquisition was not affected by the US duration.

Next, we asked whether the strength of the CR during acquisition differed between the four groups in a subset of animals analyzed above. We took recordings from muscle 17 (M17)
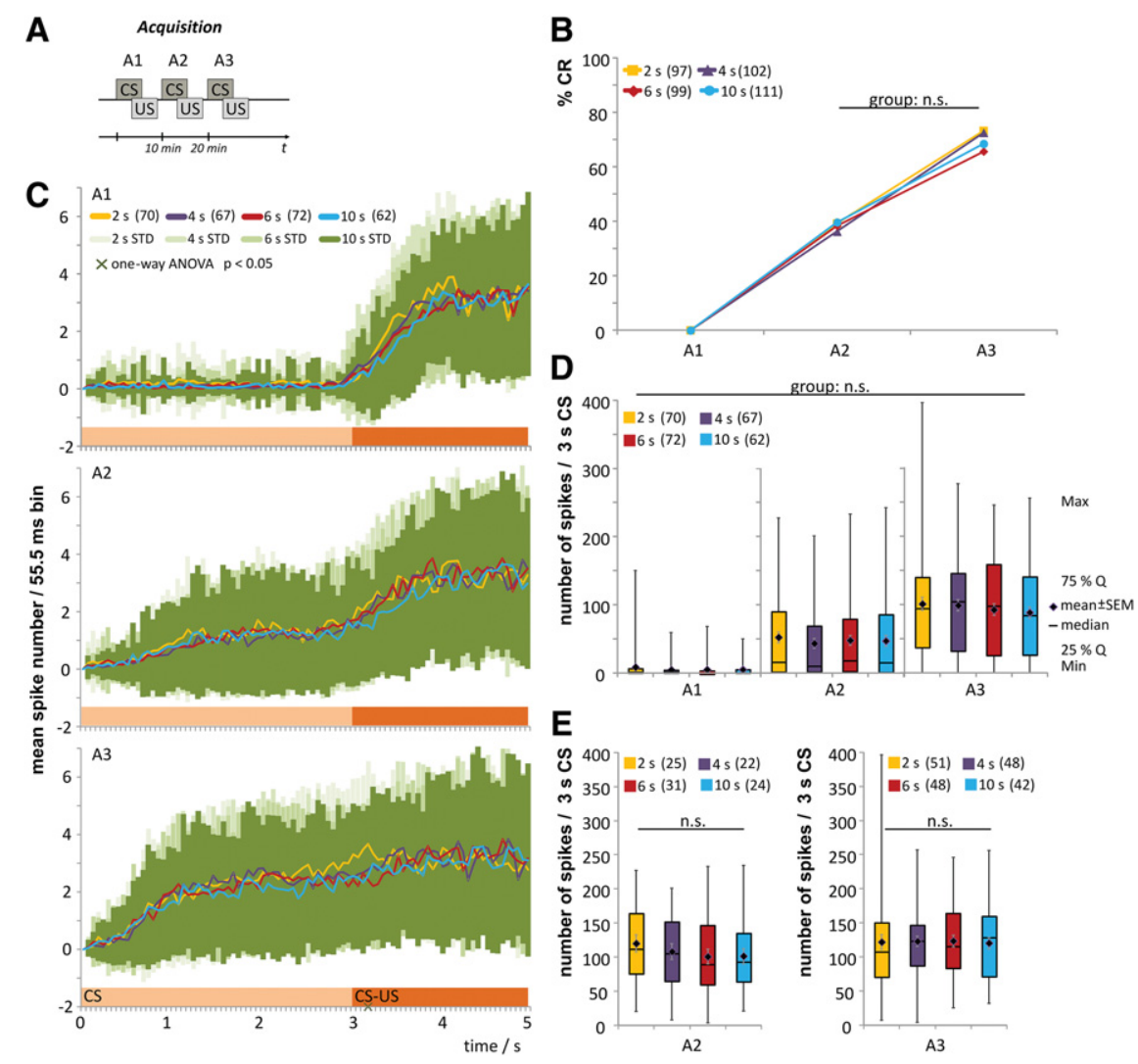

Figure 1. The probability and the strength of the CR during acquisition are not influenced by US duration. (A) Scheme of the conditioning protocol. Animals were conditioned with three CS-US pairings (A1, A2, A3) with an intertrial interval (ITI) of $10 \mathrm{~min}$. (B) Acquisition of bees that were conditioned with a US presented for $2 \mathrm{sec}$ (yellow), $4 \mathrm{sec}$ (violet), $6 \mathrm{sec}$ (red), or $10 \mathrm{sec}$ (blue). The percentage of bees that responded with a CR is plotted. The number of animals is shown in brackets. The probability of the CR during conditioning does not differ between groups. ( $C-E$ ) The strength of the CR does not differ between groups during conditioning. The myogram activity of muscle 17 (M17) was recorded and analyzed for each conditioning trial. (C) The mean myogram spike number during presentation of the CS in the three conditioning trials and the respective standard deviation (STD) are plotted for each bin and each experimental group. The light orange area represents the first 3 sec of CS presentation (CS), the orange area represents the 2 sec during which the CS and the US were presented simultaneously (CS-US). Green crosses on the $x$-axis represent significant differences $(P<0.05)$ between groups as revealed by one-way ANOVAs for each bin. (D) The number of myogram spikes during the first $3 \mathrm{sec}$ of the CS presentation is shown for each conditioning trial and each experimental group. (Diamond) mean, (SEM) standard error of the mean, (horizontal line) median, (Q) quartile. (E) The number of spikes during the first $3 \mathrm{sec}$ of the CS presentation was analyzed separately for animals that reacted with a CR during this phase. 
(Snodgrass 1956) and analyzed these recordings for each acquisition trial (A1, A2, and A3) (Fig. 1C, D) by dividing the $5 \mathrm{sec}$ of CS presentation into $55.5 \mathrm{msec}$ bins and calculating the mean spike number for every bin. Thereby, spike sequences of the 5 sec of CS presentation were generated (Fig. 1C). In A1, the activity of the M17 increased with the presentation of the US. There are no significant differences in the mean spike number between the four groups in A1. In A2 the onset of M17's activity shifted toward the CS-onset. A significant difference between the mean spike number of the 2-sec US group and the 6-sec US group was observed in one bin during US presentation (one-way ANOVA: $F_{(3,267)}=2.669, P<0.048$, Fisher's least significant difference (LSD) post hoc test: $P_{2}$ vs. $6 \mathrm{sec}=0.008$ ). In A3 the onset of M17's activity shifted further toward the CS-onset. A significant difference between the mean spike number of the 2-sec US group and one or more of the other groups was observed in three bins during US presentation (bin 56: one-way ANOVA: $F_{(3,267)}=2.807, P<$ 0.040 , LSD post hoc test: $P_{2}$ vs. $6 \mathrm{sec}=0.029, P_{2}$ vs. $10 \mathrm{sec}=0.008$; bin 57: one-way ANOVA: $F_{(3,267)}=3.587, P<0.014$, LSD post hoc test: $P_{2}$ vs. $4 \mathrm{sec}=0.039, P_{2}$ vs. $6 \mathrm{sec}=0.003, P_{2}$ vs. $10 \mathrm{sec}=$ 0.012; bin 58: one-way ANOVA: $F_{(3,267)}=2.700, P<0.046$, LSD post hoc test: $P_{2}$ vs. 6 sec $=0.005$ ).

Additionally, we analyzed the number of spikes during the first $3 \mathrm{sec}$ of CS presentation. This is the phase during which the occurrence of the CR was monitored during acquisition (Fig. 1D). The mean spike number increased in all groups from 63-78 in A1 to 196-214 in A3. This increase was significant over all groups (rmANOVA: factor trial $F_{(2,532)}=225.1, P<0.001$ ) but no differences between groups were found (factor group $F_{(3,266)}=$ $0.51, P=0.677$, group $\times$ trial interaction $\left.F_{(6,532)}=0.25, P=0.96\right)$.

Above we analyzed the M17 activity of all animals, that is, animals that responded with a CR during acquisition and animals that did not. Pooling these data might have led to a high variance of the M17 data, thereby masking an effect of the US duration on the strength of the CR. Therefore, we next analyzed the M17 activity for all trials during which an animal responded with a $\mathrm{CR}$ during the first $3 \mathrm{sec}$ of CS presentation, and asked whether the mean spike number differed between the groups (Fig. 1E). For each trial, the spike number was found not to differ between groups (one-way ANOVA: A2: $F_{(3,97)}=0.6, P=0.62$; A3: $\left.F_{(3,184)}=0.03, P=0.993\right)$. Thus, the US duration does not affect the activity of the M17 during acquisition.

Taken together, these results demonstrate that all animals learned the CS as a predictor for the US. The US duration affects neither the probability nor the strength of the CR during conditioning. We conclude from these results that the prediction of the US by the CS is not affected by the US duration.

\section{US duration experienced during acquisition does not influence the CR during extinction $24 \mathrm{~h}$ later}

We next asked whether the US duration experienced during conditioning has an impact on eLTM retention and the strength of eLTM. We examined the memory's strength by examining its re- sistance to extinction, a measure that has been used previously in experiments with free-flying honeybees (Couvillon and Bitterman 1980, 1982; Buchanan and Bitterman 1988) and other invertebrate and vertebrate animals (Annau and Kamin 1961; Tully and Quinn 1985; Federman et al. 2012).

A subset of the animals that had been conditioned in the previous experiment was exposed to five extinction trials, that is, five CS presentations (ITI $=10 \mathrm{~min}$ ), $24 \mathrm{~h}$ after acquisition (Fig. 2A). As described above, the percentage of animals responding with a CR increased during conditioning from $0 \%$ to $69.64 \%-80.00 \%$ and the probability of the CR was not affected by the US duration (rmANOVA: factor time $F_{(1,204)}=108.6, P<0.001$, factor group $F_{(3,204)}=1.3, P=0.274$, group $\times$ time interaction $F_{(3,204)}=0.24$, $P=0.872$ ) (Fig. 2B).

During extinction, the percentage of animals responding with a CR decreased in all groups from $71 \%$ to $76 \%$ in the first extinction trial (E1) to $12 \%-22 \%$ in the last extinction trial (E5). The difference between extinction trials was significant over all groups (rmANOVA: factor time $F_{(4,812)}=81.2, P<0.001$ ). No difference in CR was observed between groups (factor group $F_{(3,203)}=$ $1.7, P=0.161$, group $\times$ time interaction $\left.F_{(12,812)}=1.3, P=0.205\right)$ (Fig. 2B).

The mean spike number of the M17 during CS presentation decreased in all groups from 173-183 in E1 to 25-53 in E5. This difference is significant over all groups (rmANOVA: factor time $\left.F_{(4,548)}=64.4, P<0.001\right)$. The mean spike number did not differ between groups (factor group $F_{(3,137)}=1.2, P=0.318$, group $\times$ time interaction $\left.F_{(12,548)}=0.55, P=0.880\right)($ Fig. $2 \mathrm{C})$.

Taken together, these results demonstrate that the probability and the strength of the CR during extinction are not influenced by the duration of the US. An extinction trial consists of a single CS-only presentation. Thus, the first extinction trial
A
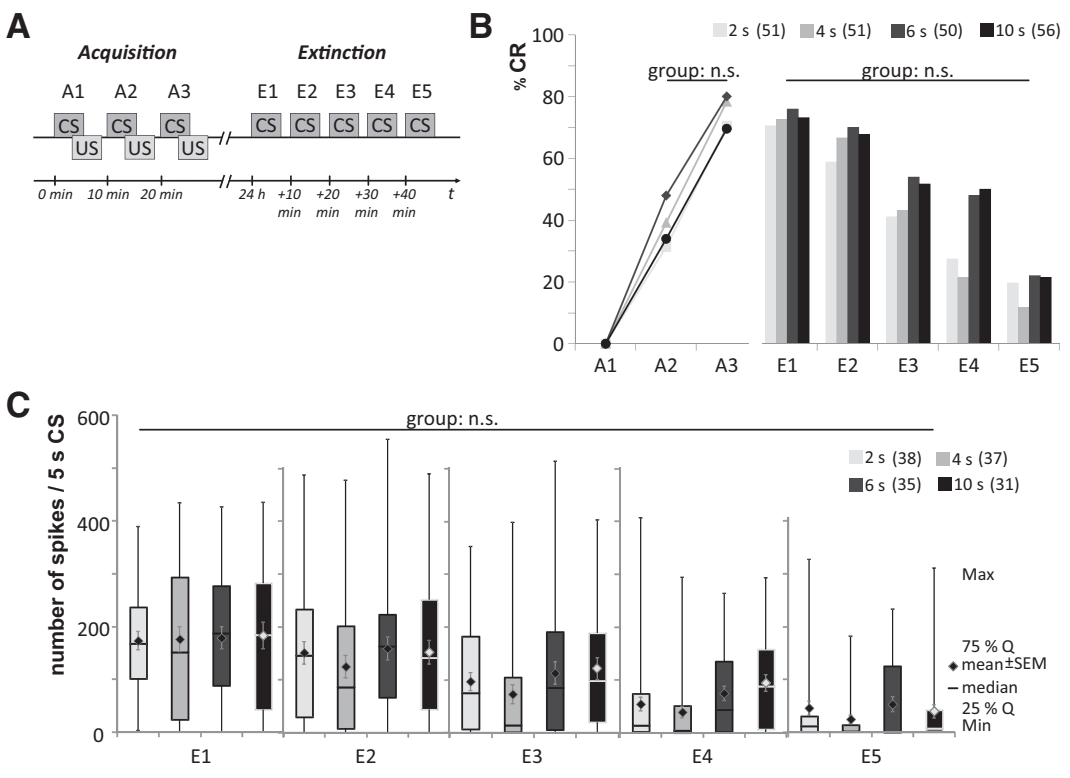

Figure 2. The probability and the strength of the CR $24 \mathrm{~h}$ after acquisition are not affected by US duration. $(A)$ Scheme of the conditioning protocol. Animals were conditioned with three CS-US pairings (A1, A2, and A3) with an intertrial interval (ITI) of 10 min. eLTM was extinguished five times (E1 $\mathrm{E5}, \mathrm{ITI}=10 \mathrm{~min}$ ) with a CS alone $24 \mathrm{~h}$ after conditioning. (B) Acquisition and extinction of bees that were conditioned with USs of different duration (2 sec: light gray, 4 sec: gray, 6 sec: dark gray, 10 sec: black). The probability of the CR does not differ between groups during acquisition and extinction. (C) The strength of the CR does not differ between groups during extinction: The activity of the M17 during extinction was recorded and analyzed. The spike number recorded during the 5 sec of CS presentation during each extinction trial is plotted for the four groups. (Diamond) mean, (SEM) standard error of the mean, (horizontal line) median, (Q) quartile. 
A
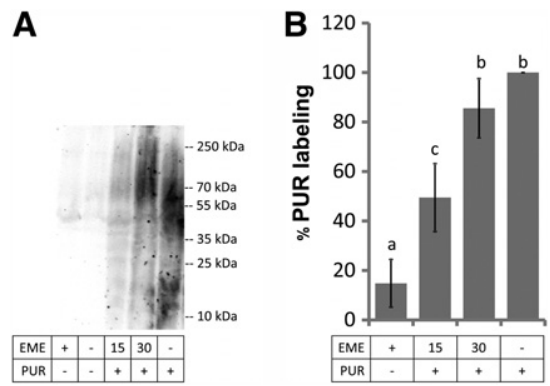

Figure 3. Inhibition of protein synthesis by emetine is reversible. $(A)$ In order to examine the protein synthesis-inhibiting effect of emetine, newly synthesized, puromycin-labeled proteins from honeybee brains were visualized with Western blots. (B) Inhibition of protein synthesis was observed when emetine was injected $15 \mathrm{~min}$ but not 30 min before puromycin application, $n=3$. Error bars represent the standard error of the mean. Different letters above bars indicate significant differences $(P<0.05)$ between values.

resembles a memory retention test when the occurrence of the CR is tested by presenting the CS. We conclude that the US duration experienced during acquisition does not affect eLTM retention or eLTM resistance to extinction, and therefore does not affect eLTM formation or the strength of the eLTM.

\section{Resistance to extinction is susceptible to protein synthesis inhibition depending on the US duration}

Next we studied whether US duration affects the molecular mechanisms underlying eLTM formation by interfering with protein synthesis, a process characteristic for the formation of eLTM. First we tested the effect of the protein synthesis inhibitor emetine on protein synthesis in honeybee brains using puromycin to label de novo synthesized proteins.

We injected emetine systemically 30 or 15 min before initiating labeling of proteins with puromycin (Schmidt et al. 2009). Emetine treatment without further puromycin labeling served as the negative control. Puromycin labeling without prior emetine incubation served as the positive control. We quantified puromycin and thus newly synthesized proteins from the honeybee brain in Western blots. Data were normalized to the positive control. Emetine treatment without further puromycin labeling did not lead to significant puromycin detection (Fig. 3, one-way ANOVA: $F_{(3,8)}=13.7, P=0.002$, LSD post hoc test: $\left.P<0.001\right)$. Significantly reduced puromycin incorporation, compared with the positive control, was observed after $15 \mathrm{~min}$ of emetine incubation $(P=0.009)$. Puromycin incorporation after $30 \mathrm{~min}$ of emetine incubation was not significantly different from the positive control $(P=0.352)$. Thus, in honeybee brains, emetine reversibly inhibits protein synthesis.

Next the effect of emetine on eLTM formation and eLTM's resistance to extinction $24 \mathrm{~h}$ after acquisition was tested. Again, four groups of honeybees were conditioned with three CS-US pairings (ITI $=10 \mathrm{~min}$ ). The US was presented for 2, 4, 6, or 10 sec. After acquisition, each group was divided into two subgroups. One hour after the onset of conditioning one group was injected with emetine $(1 \mu \mathrm{L}, 20 \mathrm{mM})$, the other with its solvent (PBS). The bees were exposed to five extinction trials (ITI $=10 \mathrm{~min}$ ) $24 \mathrm{~h}$ following conditioning (Fig. 4A).

The percentage of animals responding with a CR increased in the course of acquisition from $0 \%$ in the first acquisition trial to $54.47 \%-67.69 \%$ in the third trial. This increase was significant (rmANOVA: factor time $\left.F_{(1,503)}=116.5, P<0.001\right)$. Again no difference in CR was observed between groups (factor group $F_{(3,503)}=$
1.2, $P=0.303$, group $\times$ time interaction $\left.F_{(3,503)}=1.4, P=0.252\right)$ (Fig. 4B).

Thus, we reproduced our finding that the probability of the CR during acquisition was not affected by the US duration.

For all four US groups, the percentage of emetine- and PBS-injected animals responding with a CR decreased significantly from the first to the last extinction trial (Fig. 4C-F, rmANOVA: factor time: 2 -sec US: $F_{(4,472)}=22.4, P<0.001$. 4-sec US: $F_{(4,484)}=30.8, P<0.001$. 6 -sec US: $F_{(4,528)}=25.1, P<0.001$. 10 sec US: $\left.F_{(4,512)}=24.5, P<0.001\right)$. Thus, extinction took place. In the groups conditioned with 2-, 4-, and 6-sec US duration, the percentage of animals responding with a CR during extinction was significantly lower for emetine-injected animals than for the PBS-injected control animals (Fig. 4C-E, factor group: 2-sec US: $F_{(1,118)}=9.7, P=0.002$. 4-sec US: $F_{(1,121)}=4.5, P=0.036$. 6-sec

A
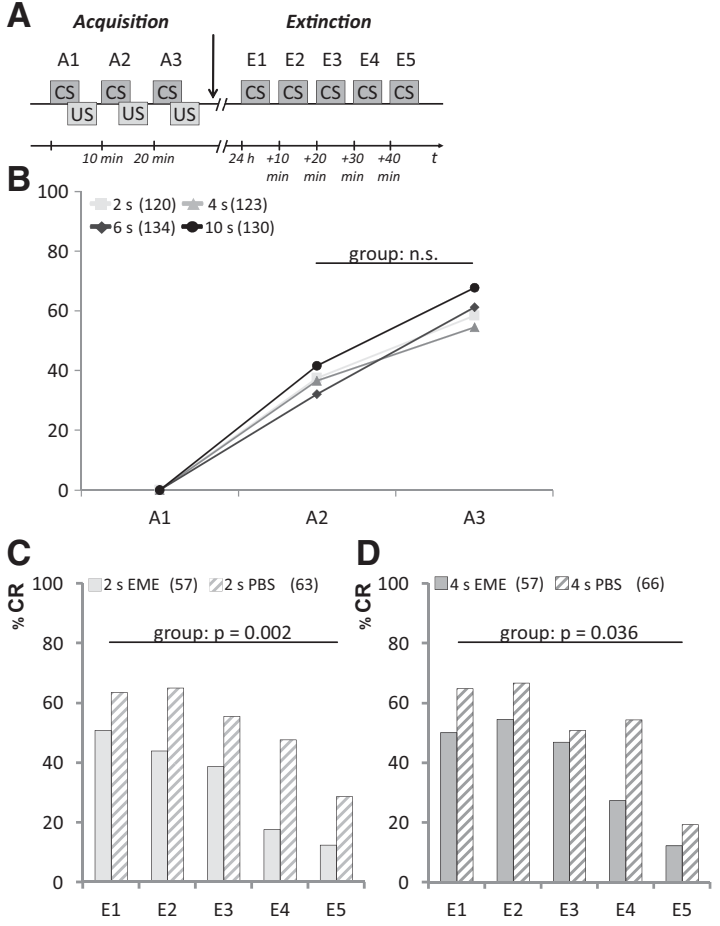

E
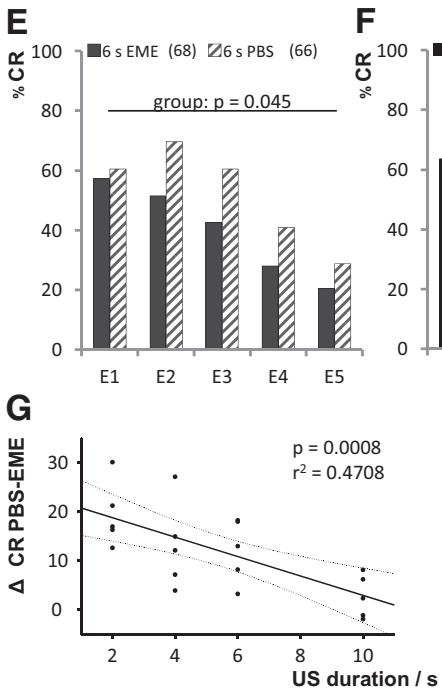

Figure 4. (Legend on next page) 
US: $F_{(1,132)}=4.1, \quad P=0.045$; group $\times$ time interaction: 2 -sec US: $F_{(4,472)}=1.0, P=0.386$. 4-sec US: $F_{(4,484)}=1.9, P=0.108$. 6-sec US: $\left.F_{(4,528)}=1.0, P=0.385\right)$. In the 10 -sec US group no difference in CR during extinction between the animals injected with emetine and those injected with PBS was observed (Fig. 4F, factor group: $F_{(1,128)}=0.2, P=0.654$. group $\times$ time interaction: $\left.F_{(4,512)}=0.45, P=0.77\right)$. In the $2-, 4-$, and 6 -sec group differences between the emetine- and the PBS-treated bees in the percentage of animals responding with a CR at the first extinction trial (E1) were not significant at (LSD post hoc test: 2 -sec US: $P=0.14$. 4-sec US: $P=0.08$. 6-sec US: $P=0.69$ ). An extinction trial consists of a single CS-only presentation. Therefore, the first extinction trial resembles a memory retention test. Accordingly, we conclude that the formation of eLTM is not susceptible to emetine. However, in the 2-, 4-, and 6-sec groups susceptibility to emetine was observed over the course of extinction. This finding indicates that the resistance to extinction is inhibited following the application of emetine in animals experiencing a US that lasts 2,4 , or 6 sec. We conclude that building up eLTM strength depends on protein synthesis during memory formation.

Next we asked whether the amount of amnesia induced by protein synthesis inhibition over the course of extinction depends on the US duration experienced during conditioning. Using a linear regression analysis we analyzed the relationship between the effect of the protein synthesis inhibitor during the course of extinction and the US duration. For every extinction trial and every US group, the difference between the percentage of animals responding with a CR in the emetine-injected and the PBS-injected group was calculated. This difference represents the amount of amnesia induced by emetine and was plotted against the US duration (Fig. 4G). The linear regression analysis revealed a negative linear relationship $\left(P<0.001, r^{2}=0.471\right)$ between the US duration and the amount of amnesia induced over all extinction trials. Thus, the US duration affects the amount of amnesia over the course of extinction induced by protein synthesis inhibition: The longer the US duration experienced during conditioning, the less amnesia was observed during extinction $24 \mathrm{~h}$ after conditioning.

Taken together, these results demonstrate that emetine weakens eLTM's resistance to extinction $24 \mathrm{~h}$ after acquisition. This susceptibility for emetine depends on the US duration experienced during acquisition. We interpret the resistance to extinction as a measure for a memory's strength. Accordingly, the duration of the US is a parameter that regulates protein synthesis underlying eLTM's strength.

\section{Protein synthesis inhibition weakens eLTM's resistance to extinction depending on the US duration}

We observed that emetine does not weaken eLTM's resistance to extinction when animals were conditioned with a US of 10-sec duration. Because we find that emetine reversibly inhibits protein synthesis in honeybees, we hypothesized that the time point of susceptibility to the inhibitor shifts depending on the US duration. In order to test this hypothesis we examined the effect of emetine on resistance to extinction $24 \mathrm{~h}$ after acquisition with a US of 10 sec duration.

Honeybees were conditioned with three CS-US pairings (ITI $=10 \mathrm{~min}$ ) and a US of $10 \mathrm{sec}$. After conditioning, the animals were divided into three groups. Each of these groups consisted of two subgroups of animals that behaved identically during conditioning. One subgroup served as the control receiving two PBS injections. The animals received the first injection $1 \mathrm{~h}$ and the second injection $1.5 \mathrm{~h}$ after the onset of conditioning (PBS/PBS). The second subgroup, the experimental group, received either one or two emetine injections. The first experimental group received an emetine injection $1 \mathrm{~h}$ after conditioning and a PBS injection $1.5 \mathrm{~h}$ after conditioning (EME/PBS). The second experimental group received two emetine injections. The animals received the first injection $1 \mathrm{~h}$ and the second injection $1.5 \mathrm{~h}$ after conditioning (EME/EME). The third experimental group received a PBS injection $1 \mathrm{~h}$ after conditioning and an emetine injection $1.5 \mathrm{~h}$ after conditioning (PBS/EME). Thus, six groups were examined in this experiment: three control groups (PBS/PBS) and three experimental groups (EME/PBS; EME/EME; PBS/EME).

The percentage of animals responding with a CR increased during conditioning. Bees increased their responses in the course of acquisition from $0 \%$ in the first acquisition trial to EME/PBS: 62.9-63.93 EME/EME: 68.25-68.42 PBS/EME: 58.82\%-60\% in the third trial. This increase was significant (rmANOVA, factor time: EME $/ \mathrm{PBS} F_{(1,116)}=11.5, P<0.001 ; \mathrm{EME} / \mathrm{EME} F_{(1,111)}=$ $21.2, P<0.001$; PBS $/$ EME $\left.F_{(1,102)}=5.8, P=0.018\right)$. No difference in CR was observed between the experimental and the control group (factor group: EME/PBS $F_{(1,116)}=0.004, P=0.948$; EME/ EME $F_{(1,111)}=0.056, P=0.813 ;$ PBS $/ \mathrm{EME} F_{(1,102)}=0.05, \quad P=$ 0.833 , group $\times$ time interaction: EME $/ \mathrm{PBS} F_{(1,116)}=0.01, P=$ 0.933 ; EME $/$ EME $F_{(1,111)}=0.83, P=0.365 ;$ PBS $/$ EME $F_{(1,102)}=$ $0.2, P=0.657)$ (Fig. 5A-C).

One emetine injection $1 \mathrm{~h}$ after the onset of conditioning did not affect resistance to extinction $24 \mathrm{~h}$ later (Fig. 5A, rmANOVA: factor time: $F_{(1,116)}=7.9, P=0.006$. factor group: $F_{(1,116)}=0.22$, $P=0.637$. group $\times$ time interaction: $\left.F_{(1,116)}=0.54, P=0.463\right)$ replicating finding of the previous experiment. However, animals that were emetine-injected twice showed a significantly lower performance during extinction than their control group (Fig. 5B, factor time: $F_{(1,111)}=10.5, P=0.002$. factor group: $F_{(1,111)}=4.9, P=$ 0.029 . group $\times$ time interaction: $\left.F_{(1,111)}=0.10, P=0.751\right)$. An emetine injection $1.5 \mathrm{~h}$ after acquisition affected the retention scores during extinction $24 \mathrm{~h}$ later as well (Fig. 5C, factor time: $F_{(1,102)}=21.6, P<0.001$. factor group: $F_{(1,102)}=5.8, P=0.018$. group $\times$ time interaction: $\left.F_{(1,102)}=0.71, P=0.401\right)$ (Fig. 5).

Taken together, our results demonstrate that one emetine injection $1 \mathrm{~h}$ after acquisition with a $10 \mathrm{sec}$ US presentation does not affect the CRs during extinction $24 \mathrm{~h}$ after acquisition, whereas two emetine injections, one $1 \mathrm{~h}$ and the second $1.5 \mathrm{~h}$ as well as one injection $1.5 \mathrm{~h}$ after acquisition affect these retention scores. This finding indicates that the susceptibility of eLTM formation to emetine is shifted to a later time point after acquisition as compared with conditioning with a shorter US. Thus, we conclude

Figure 4. The eLTM's resistance to extinction is susceptible to emetine depending on the US duration. $(A)$ One hour after the onset of conditioning with three $C S-U S$ pairings ( $A 1, A 2$, and $A 3$ ) the protein synthesis inhibitor emetine or its solvent PBS were injected systemically (arrow). eLTM was extinguished five times (E1-E5) $24 \mathrm{~h}$ after conditioning. (B) Acquisition of bees that were conditioned with a US presented for $2 \mathrm{sec}$ (light gray), $4 \mathrm{sec}$ (gray), $6 \mathrm{sec}$ (dark gray), or $10 \mathrm{sec}$ (black). The percentage of bees that responded with a CR is plotted. The number of animals is shown in brackets. The probability of the CR does not differ between groups during conditioning. $(C-F)$ Extinction of bees that were conditioned with a US presented for $2 \mathrm{sec}(C), 4 \mathrm{sec}(D), 6 \mathrm{sec}(E)$, or $10 \mathrm{sec}$ $(F)$ and injected with the protein synthesis inhibitor emetine (EME, filled bars) or PBS (striped bars). Presented is the percentage of bees that responded with a CR during extinction. The emetine-injected animals of the groups that were trained with the US durations 2, 4, or $6 \mathrm{sec}$ showed a lower performance than the respective PBS-injected control animals. (G) For every extinction trial and every US-group, the difference between the percentage of animals responding with a $C R$ in the emetine-injected and the PBS-injected group was calculated ( $\Delta C R$ PBS-EME) and plotted against the US duration. A linear regression analysis tested for a linear relationship between US duration and the difference between the CRs. The analysis revealed a negative linear relationship $\left(P<0.001, r^{2}=0.471\right)$ between US duration and the difference between the CRs of PBS- and EME-injected animals. 
A

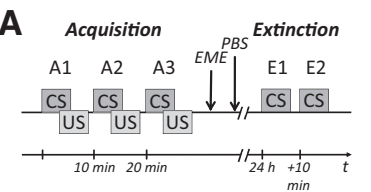

DEME/PBS (61) ZZPBS/PBS (62)

B

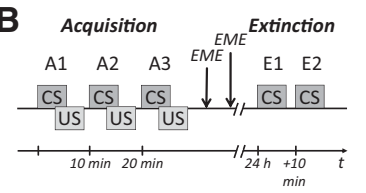

$\square \operatorname{EME} / \mathrm{EME}(63) \square \mathrm{PBS} / \mathrm{PBS}(57)$

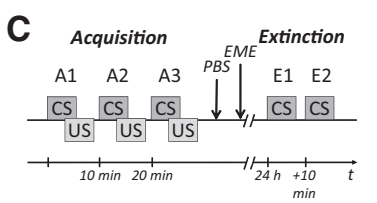

- $P B S / E M E(55) \quad Z P B S / P B S(51)$

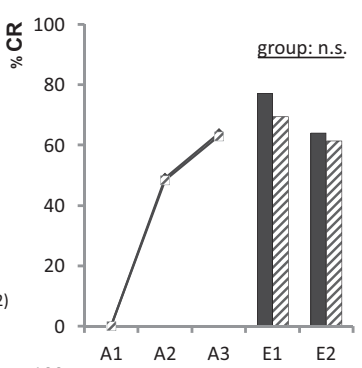

똥 100

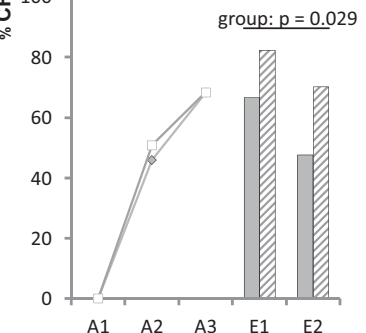

A1 A2 A3 E1 E2

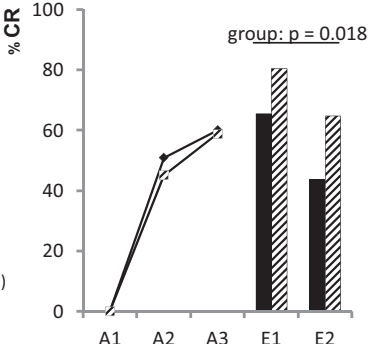

A1 A2 A3 E1 E2

Figure 5. Susceptibility to emetine is shifted after conditioning with a $10 \mathrm{sec}$ US. The protein synthesis inhibitor emetine (EME) or its solvent PBS were injected systemically (arrow) $1 \mathrm{~h}$ and $1.5 \mathrm{~h}$ after the onset of conditioning with three CS-US pairings (A1, A2, and A3). The eLTM was extinguished two times (E1-E2). Animals were conditioned with a 10-sec US. Shown is the percentage of bees that responded with a CR during acquisition and extinction. $(A)$ The experimental group (gray, filled bars) was first injected with emetine $1 \mathrm{~h}$ after acquisition. The second injection, $1.5 \mathrm{~h}$ after acquisition, was a PBS injection. The control group was injected with PBS at both time points (gray, striped bars). One emetine injection $1 \mathrm{~h}$ after acquisition did not affect the eLTM's resistance to extinction. (B) The experimental group (light gray, filled bars) was injected with emetine 1 and $1.5 \mathrm{~h}$ after acquisition. The control group was injected with PBS at both time points (light gray, striped bars). An emetine double-injection led to a lower performance during extinction compared with the PBS-injected control group. (C) The experimental group (black, filled bars) was injected with PBS $1 \mathrm{~h}$ after conditioning. The second injection, $1.5 \mathrm{~h}$ after conditioning, was an emetine injection. The control group was injected with PBS at both time points (black, striped bars). An emetine injection $1.5 \mathrm{~h}$ after conditioning led to a lower performance compared with the PBS-injected control group and thus to a reduced resistance to extinction.

that the duration of US presentation impacts the onset of protein synthesis necessary for building up an eLTM's strength.

\section{Duration of US presentation affects the amount of sucrose solution imbibed}

Finally we asked whether animals that were conditioned with different US durations might have imbibed different amounts of sucrose solution. The toothpicks we were using in the previous experiments to present the US were only moistened with sucrose solution. Therefore we hypothesized that animals do not take up different amounts of sucrose solution when receiving compound US of different duration. To test this hypothesis we measured the amount of sucrose solution taken up by weighing the animals in- dividually before and after presenting sucrose, similar to the way the US is presented during a conditioning trial: First, an animal's PER was elicited by touching both antennae with a toothpick moistened with $1.25 \mathrm{M}$ sucrose solution. The mean time it takes to elicit the PER is $1.33 \mathrm{sec}( \pm 0.49 \mathrm{SD}, N=15)$. After eliciting the PER, the proboscis was touched with the sucrose-moistened toothpick and the animal was allowed to lick the sucrose solution from the toothpick until the sucrose presentation time $(2,4,6$, or $10 \mathrm{sec}$ ) expired. The difference between the animal's weight before and after sucrose presentation was calculated. This difference is taken to represent the amount of sucrose solution taken up by a bee.

The median amount imbibed by a bee during the presentation of the sucrose increased from a presentation of 2 sec to a presentation of $10 \mathrm{sec}$. The sucrose solution amount was significantly different between groups receiving a compound US for 2, 4, 6, and $10 \mathrm{sec}$ (Kruskal-Wallis Test: $\mathrm{df}=3, H=22.69, P<0.0001$ ) (Fig. $6)$. Between the $10 \mathrm{sec}$ group and all other groups the median amount was significantly different (Mann-Whitney test: 10 versus 2 sec: $\mathrm{df}=1, U=133, P<0.0001,10$ versus 4 sec: $\mathrm{df}=1, U=233$, $P<0.0036,10$ versus 6 sec: $\mathrm{df}=1, U=312, P<0.0065)$. In addition, the median amount imbibed by animals receiving $2 \mathrm{sec}$ was significantly different from animals receiving a 6-sec sucrose presentation (Mann-Whitney test: 2 versus 6 sec: $\mathrm{df}=1, U=237$, $P<0.008$ ), but not between 2 and 4 sec (Mann-Whitney test: $\mathrm{df}=1, U=221, P<0.0481$, Bonferoni corrected $P<0.144)$ and 4 and $6 \mathrm{sec}$ (Mann-Whitney $U: \mathrm{df}=1, U=0.6, P<0.61$ ) (Fig. 6).

Taken together these results demonstrate that animals that receive a $10 \mathrm{sec}$ presentation of the US imbibe significantly more sucrose than animals receiving the US for 2, 4, and 6 sec. Thus, the amount of sucrose solution taken up from a sucrosemoistened toothpick depends on the duration of the US presentation.

\section{Discussion}

We report that the probability and the strength of the conditioned response (CR) during acquisition and $24 \mathrm{~h}$ later during extinction are not affected by the US duration. The occurrence of the

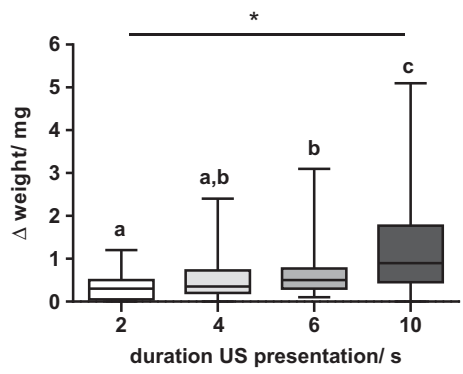

Figure 6. Duration of US presentation affects the amount of sucrose solution imbibed. The difference between the animal's weight before and after US presentation is affected by the duration of the US presentation indicating that the amount of sucrose solution imbibed during acquisition depends on the US duration. US presentation started with eliciting an animals' proboscis extension response (PER) by touching both antennae with a toothpick moistened with $1.25 \mathrm{M}$ sucrose solution and was followed by letting the animal lick the solution from the toothpick until the US presentation time $(2,4,6$, or $10 \mathrm{sec})$ expired. Single animals were weighed before and after a US presentation. The weight difference was calculated and plotted ( $\Delta$ weight $/ \mathrm{mg}$ ) against the duration of US presentation (duration US presentation/sec). Here the median is shown. The box extends from the 25th to 75th percentiles; whiskers are plotted down to the minimum and up to the maximum value. $N=25(2 \mathrm{sec}), N=26$ $(4 \mathrm{sec}), N=32(6 \mathrm{sec}), N=32(10 \mathrm{sec})$. Significant differences at $P>$ 0.05 . Different letters above boxes and $\left(^{*}\right)$ indicate significant differences. 
conditioned response toward the CS indicates that the CS induces a prediction about the US (Schultz 2007). We conclude that the prediction of the US is not affected by the US' duration. Thus, in our experiments animals learn and memorize the predictability of the US independent of the US duration, and form an eLTM about it. However, we find that resistance to extinction is susceptible to emetine in a US-dependent manner. Because we interpret the resistance to extinction as an indication of a memory's strength, we conclude that building up the eLTM's strength depends on protein synthesis following learning and that the dynamics of protein synthesis are affected by the US duration.

In our current experiments the number of CS-US trials, the interval between CS and US onset, the duration of the CS, and the interval between CS onsets of subsequent acquisition trials were held constant. Because the CR during acquisition and extinction $24 \mathrm{~h}$ later does not differ between groups that were trained with different US durations we conclude that these parameters were sufficient for the CS to become a predictor for the US. Indeed, several studies in honeybees and vertebrates indicate that timing variables such as the duration of the CS, the interval between CS and US onset, the intertrial interval and the number of trials are directly correlated with the strength of the CR during learning and memory retention (Menzel et al. 1993, 2001; Friedrich et al. 2004; Harris 2011; Kirkpatrick 2014).

In contrast, varying the US duration alters the dynamics of protein synthesis required to strengthen the eLTM. To date we do not know whether it is the US duration itself or rather a covarying parameter that is responsible for this effect. We find that the sucrose amount taken up by honeybees in the 10-sec US group is significantly larger than the amount taken up by the animals that received compound USs of 2, 4, and $6 \mathrm{sec}$. Thus it might be that it is not the US duration but rather the US amount that is the cause for the altered onset of protein synthesis. Interestingly, honeybees already form an association between CS and US when only the antennae are stimulated with sucrose solution (Bitterman et al. 1983; Sandoz et al. 2002; Wright et al. 2007). However, when bees are fed on water during the presentation of a US instead of sucrose solution, although the PER was elicited with sucrose solution, they respond with a lower probability to the conditioned odor at the eLTM retention test suggesting that a postingestive feedback about the quality or quantity of the US might influence eLTM strength (Wright et al. 2007). In the fruit fly, Drosophila melanogaster, two parallel appetitive reinforcement pathways mediate reward memory formation, one for the sweet taste and a second pathway underlying the nutritional value of a sugar reward. Sweet-tasting rewards with no nutritional value result in short-term memories whereas rewards with a nutritional value lead to long-term memories (Burke and Waddell 2011; Burke et al. 2012). Thus, it seems likely that the sweetness of the $1.25 \mathrm{M}$ sucrose solution that was presented to all groups as a US was sufficient for the animals to learn about the association of CS and US. Moreover, the shortest presentation of the compound US ( $2 \mathrm{sec}$ ) and thus the smallest amount of sucrose taken up by the animals seems to be sufficient to form an eLTM about the CS-US association with a similar strength in the four groups conditioned with different US durations. However, the duration of the US, or a parameter covarying with a US duration, is crucial for modifying the dynamics of protein synthesis underlying eLTMs strength.

Our finding that the US duration does not impact the CR during conditioning is supported by findings that the duration of sucrose uptake by honeybees does not impact color learning in free-flying bees (Menzel 1968). However, in free-flying bees the reward duration and the reward amount impact the bees' correct choices for a rewarded color stimulus shortly after learning (Menzel 1968; Menzel and Erber 1972; Couvillon et al. 1991; Couvillon and Bitterman 1993). Moreover, in free-flying bees the reward amount affects a memory's resistance to extinction (Buchanan and Bitterman 1988, 1989).

We did not observe an effect of the US duration, and thus the amount of sucrose, on the eLTM's resistance to extinction. Therefore, our data seem to contradict the findings by Bitterman and colleagues. However, we investigated the effect of US duration on resistance to extinction $24 \mathrm{~h}$ following conditioning whereas Buchanan and Bitterman $(1988,1989)$ investigated resistance to extinction and choice behavior minutes after conditioning. Thus we hypothesize that short-term and long-term memories might differ in the dependency of their strength on the US duration and amount.

We demonstrate that the US duration modulates the dynamics of protein synthesis underlying eLTM's strength. No differences in the resistance to extinction and thus, in eLTM strength, was observed between groups conditioned with different US durations without inhibiting protein synthesis $24 \mathrm{~h}$ after conditioning. Accordingly, the relevance of this rather molecular phenomenon remains unclear.

We demonstrate an effect of emetine on the resistance to extinction. In vertebrate cells and in the protozoa Plasmodium falsiparum emetine binds to the $40 \mathrm{~S}$ ribosomal subunit thereby blocking translocation during elongation (Jimenez et al. 1977; Madjar et al. 1982; Wong et al. 2014). A phylogenetically highly conserved factor regulating translation elongation is the elongation factor eEF2 (Kim and Graham 2008). eEF2 is phosphorylated within the first $20 \mathrm{~min}$ following learning and dephosphorylated $>30$ min later (Belelovsky et al. 2005; Im et al. 2009). General protein synthesis is blocked following the phosphorylation of eEF2 (Ryazanov et al. 1988; Marin et al. 1997). Thus, findings by Belelovsky et al. (2005) and Im et al. (2009) suggest that during the first $30 \mathrm{~min}$ after learning general protein synthesis is blocked. An inhibitor of elongation, like emetine, most likely does not affect general protein synthesis during this time period, but only after $30 \mathrm{~min}$ when elongation is no longer inhibited and general protein synthesis is taking place. In line with these findings, we observe an effect of emetine injected $40 \mathrm{~min}$ after the last conditioning trial in the 2-, 4-, and 6-sec group. However, in the 10 -sec group, an effect of emetine is observed only 30 min later. Thus it could be that in the 10 -sec group elongation is inhibited for a longer time period intrinsically so that susceptibility to emetine is visible at a later time point.

A general down-regulation of elongation results in the translation of a small subset of mRNAs that encode specific synaptic proteins (Scheetz et al. 2000; Chotiner et al. 2003; Davidkova and Carroll 2007; Park et al. 2008). Accordingly, in the 10-sec group this small subset of transcripts might be translated during a prolonged down-regulation of general translation. Because these transcripts are preferentially expressed in dendrites, Heise et al. (2014) suggest that the eEF2-dependent regulation of elongation "may be utilized by neurons to implement proteomic changes at dendrites to facilitate activity-dependent plastic changes at the synapses." Thus in the 10-sec group a prolonged protein synthesis of a few synaptic proteins might take place that underlies the modification of activity-dependent changes at synapses by subsequent neuronal activity. A shifted protein synthesis as we observe it in the 10-sec group might therefore modify synaptic plasticity following subsequent neuronal activity although it does not result in direct behavioral effects.

The starting point of this study was the finding that the duration of the US presented during classical conditioning is critical for the protein synthesis-dependent formation of extinction memories in the honeybee following extinction of eLTM (Stollhoff and Eisenhardt 2009). We interpreted this result as indicating that the duration of the sucrose stimulus impacts eLTM formation such that extinction memory formation is affected. Our recent 
finding of an altered onset of translation in animals receiving a long-lasting compound US during conditioning might support this conclusion if the hypothesis holds true that an altered general protein synthesis modifies synaptic plasticity upon subsequent neuronal activation (Heise et al. 2014). In this case conditioning with a long-lasting compound US might result in an altered proteome of synapses activated during conditioning. During extinction, when these synapses are reactivated, their plasticity might be modified such that protein synthesis-dependent formation of extinction long-term memory takes place. In contrast, conditioning with a short US might not alter the proteome of participating synapses and reactivating these synapses by extinction might therefore not result in protein synthesis-dependent formation of an extinction long-term memory.

Taken together, we conclude that the US duration does not affect the predictability of the US during conditioning and during memory retention $24 \mathrm{~h}$ later. However, the US duration affects the onset of protein synthesis underlying the eLTM's strength. We hypothesize that the learning-induced shift of protein synthesis might be a mechanism that underlies extinction memory formation by modifying plastic changes at the synapses reactivated during extinction.

\section{Materials and Methods}

The experiments were conducted during the spring and summer months of 2010-2014 in Berlin, Germany. One day prior to the start of an experiment, at 2 p.m., foraging honeybees were caught at the entrance of the hive and transferred to the laboratory. Bees were immobilized in small glass vials by cooling and harnessed in small plastic tubes. At 4 p.m. on the same day the bees were fed to satiation with $0.88 \mathrm{M}$ sucrose $(30 \mathrm{~g} / 100 \mathrm{~mL}$ white refined household sugar dissolved in tap water). On subsequent evenings of the experiment, bees were fed no $>16 \mu \mathrm{L}$. During nights and between experimental manipulations, the bees were kept in a dark and humid box at room temperature (Felsenberg et al. 2011).

\section{Olfactory conditioning of the PER}

Conditioning started at 10 a.m. and consisted of three trials with an intertrial interval (ITI) of $10 \mathrm{~min}$. Clove oil (Bombastus-Werke AG) served as the conditioned stimulus (CS). The oil ( $4 \mu \mathrm{L})$ was applied to a piece of filter paper that was put into a plastic syringe (B. Braun Melsungen AG). Sucrose solution (1.25 M, 43 g/100 mL white refined household sugar dissolved in tap water) served as the US. The US is a so called compound US (Bitterman et al. 1983): US presentation starts with eliciting the PER by touching the bee's antennae with a sucrose-moistened toothpick and subsequently touching the proboscis allowing animals to lick the sucrose solution for the remaining time. The presentation of the entire compound US lasted 2, 4, 6, or $10 \mathrm{sec}$. The mean time it takes to elicit the PER is $1.33 \mathrm{sec}( \pm 0.49 \mathrm{SD}, N=15)$. The remaining time an animal spends licking the sucrose solution from the toothpick varies according to the overall duration of the compound US, which we defined in this study as "US duration."

Each trial started with a $10-\mathrm{sec}$ placement phase during which a bee was placed in the setup in front of a ventilation pipe. The CS presentation ( $5 \mathrm{sec}$ ) started $3 \mathrm{sec}$ before the US onset and stopped 2 sec after the US onset. Thus, the CS presentation overlapped the US presentation for 2 sec.

\section{Extinction}

Extinction was induced by presenting the CS $\sim 24 \mathrm{~h}$ after conditioning (ITI = $10 \mathrm{~min}$ ). The extinction protocol was the same as for conditioning, but without presentation of the US.

During conditioning, a bee scored positive when it extended its proboscis between the onset of the CS and the presentation of the US ( $3 \mathrm{sec}$ ). During extinction trials, a bee scored positive when it extended its proboscis during CS presentation ( $5 \mathrm{sec}$ ).

\section{Quantification of the CR}

Extracellular recordings of muscle 17 (M17) were performed during conditioning and extinction (Rehder 1987; Smith and Menzel 1989a,b). Harnessed honeybees were placed into recording devices, that is, metal tubes housing the connection to the amplifier and the electrodes (silver wire, $0.018 \mathrm{~mm}$, Teflon insulated except for the tip, Advent Research Materials Ltd.). The recording electrode was inserted into the bee's head capsule at the horizontal line between the right compound eye and the median ocellus. The reference electrode was placed into the contralateral compound eye. The CS was applied via an olfactometer controlled by Spike2 (Cambridge Electronic Design Ltd.). Instructions to mark and ensure the precise timing of placement and CS- and US- on- and offsets were programmed with Spike 2 and replayed via loudspeakers. Signals were recorded, visualized, and processed with Spike2 on a commercially available PC. One conditioning or extinction trial lasted $60 \mathrm{sec}$.

\section{Behavioral pharmacology}

At different time points after the onset of conditioning, that is, 1 or $1.5 \mathrm{~h}$ later, $20 \mathrm{mM}$ emetine (Sigma-Aldrich) or its solvent phosphate buffered saline (PBS, $137 \mathrm{mM} \mathrm{NaCl}, 2.7 \mathrm{KCl} \mathrm{mM}, 8$ $\mathrm{mM} \mathrm{Na}_{2} \mathrm{HPO}_{4}, 1.4 \mathrm{mM} \mathrm{KH}_{2} \mathrm{PO}_{4}$, adjusted to $\mathrm{pH}$ 7.2) were injected manually into the bee's flight muscle using a calibrated glass capillary (Selzer $\mathrm{GmbH})$. For a detailed description of the injection procedure see Felsenberg et al. (2011).

\section{Exclusion criteria and data analysis}

Animals that extended their proboscis in the experimental setup during the $3 \mathrm{sec}$ of CS presentation in the first conditioning trial were excluded from the analyses. Animals that did not respond with a PER to the US were excluded. To test whether the animals were capable of extending their proboscis during extinction trials, the PER was elicited with a sucrose-moistened toothpick at the end of each experiment. Animals that did not respond with a PER to the sucrose were excluded from the analyses.

For the M17 analyses, all animals that demonstrated a stable electromyogram over the entire experiment and fulfilled the above criteria were analyzed. Muscle recordings took place throughout the trial. The 5 sec of CS presentation were analyzed. This phase was divided into 90 bins, each being 55.5-msec long. The number of spikes occurring in each bin was counted. A peristimulus time histogram (PSTH) was calculated for each animal and each trial. Spike sequences were calculated from the PSTHs by calculating the mean of the M17 spike number of all animals of one experimental group for each bin. Differences between experimental groups were tested with one-way ANOVAs for each bin. Differences were considered to be significant if $P<0.05$. Fisher's least significant difference (LSD) post hoc test was used for post hoc comparisons. The M17 spike number during a certain time period was assessed by summing up all spikes for each trial during this phase. Differences between groups were assessed with repeated-measures ANOVAs or one-way ANOVAs. Differences were considered to be significant if $P<0.05$.

The behavioral data were tested with repeated-measures ANOVAs (Lunney 1970). An LSD post hoc test was used for post hoc comparisons. Differences were considered to be significant if $P<0.05$.

\section{Quantification of de novo protein synthesis}

Bees were caught, harnessed, fed and kept overnight as described above. In addition, bees were fed $4 \mu \mathrm{L}, 0.88 \mathrm{M}$ sucrose the next morning and windows were cut into the bee's head capsule. Emetine $(20 \mathrm{mM})$ was injected into the flight muscle as described above. Emetine was incubated for 15 or $30 \mathrm{~min}$. At the end of the emetine incubation, $1 \mu \mathrm{L}, 20 \mathrm{mM}$ puromycin (Sigma-Aldrich, solved in PBS) was applied into the head capsule through the window. Puromycin was incubated for $60 \mathrm{~min}$. After puromycin incubation, the bees were anesthetized by cooling on ice, the head capsule was opened further and the glands and trachea were 
removed. The brain was removed from the head capsule and immediately stored in ice in homogenization buffer (modified after Jarome et al. 2012; $38.4 \mathrm{mM}$ Tris- $\mathrm{HCl}, 150 \mathrm{mM} \mathrm{NaCl}, 1.3 \mathrm{mM}$ EDTA, $1 \mathrm{mM}$ NaF, $5 \mu \mathrm{M}$ PMSF, $210 \mu \mathrm{M}$ leupeptin, $15 \mu \mathrm{M}$ aprotinin, $1 \%$ SDS, $1 \mathrm{mM}$ sodium orthovanadate). One sample consisted of four brains. Once all brains of one sample were collected, the sample was frozen at $-20^{\circ} \mathrm{C}$. For Western blot analyses, the samples were defrosted, homogenized in three cycles (30 sec each) in a SpeedMill (Analytic Jena) and centrifuged for $1 \mathrm{~min}$. Equal volumes of the supernatant were subjected to SDS-PAGE and transferred to polyvinylidene difluoride membranes. The membranes were incubated in blocking buffer (3\% BSA, 1\% Tween 20, 150 $\mathrm{mM} \mathrm{NaCl}, 10 \mathrm{mM}$ Tris) for $1 \mathrm{~h}$ at room temperature and afterward overnight with the primary antibody (12D10, Millipore) diluted 1:5000 in blocking buffer at $4^{\circ} \mathrm{C}$. The membranes were washed with washing buffer (1\% Tween $20,150 \mathrm{mM} \mathrm{NaCl}, 10 \mathrm{mM}$ Tris) and incubated with the secondary antibody (antimouse: Calbiochem) diluted 1:10,000 in blocking buffer for $1 \mathrm{~h}$. After washing with washing buffer, the membranes were developed by enhanced chemiluminescence (ECL) detection (ECL system, PerkinElmer). The signals were captured with an LAS-1000 camera and the software Image Reader LAS1000 2.60 (Fujifilm). For quantification, the signals were analyzed using the software ImageJ. Signals from 15 to $250 \mathrm{kDa}$ were measured in each lane. For each Western blot the background was determined by measuring the signal of a lane loaded with brain homogenate from animals not treated with emetine or puromycin. This signal was subtracted from the signal of each lane on the blot. Data were achieved by normalizing the signals from emetine-treated animals to the signal from animals not treated with emetine, but with puromycin (100\% puromycin incorporation $=100 \%$ protein synthesis). Differences between groups were tested with a one-way ANOVA. Differences were considered to be significant if $P<0.05$.

\section{Measuring the amount of sucrose solution imbibed during US presentation}

During conditioning a compound US is presented. A US presentation consists of eliciting the proboscis extension response by touching both antennae with sucrose solution (1.25 M). Subsequently the proboscis is touched and the bee is allowed to lick the sucrose solution until the duration of the compound US expires. In order to measure the amount of sucrose solution taken up by a bee during the presentation of the US the honeybee's PER was elicited by touching both antennae with a toothpick moistened with $1.25 \mathrm{M}$ sucrose solution. Subsequently the bee's proboscis was touched with the toothpick and the bee was allowed to lick the sucrose solution from the toothpick until the US presentation time $(2,4,6$, or $10 \mathrm{sec})$ expired. This procedure is similar to the US presentation during a conditioning trial (see above). Single animals were weighed before and after this presentation of sucrose solution with an analytical balance (Mettler AJ 50, Mettler-Toledo). The weight difference was calculated for every animal. Differences between all groups were tested for significance with a Kruskal-Wallis test. Differences between two groups were tested with a Mann-Whitney test and corrected with a Bonferoni correction where a group was tested more than once. Statistical tests were carried out with Prism 6 (Graph Pad Software).

\section{Competing Interest Statement}

The authors declare no competing financial interests.

\section{Acknowledgments}

K.M. and D.E. designed the study. K.M., M.K.G., C.L., L.M., C.B., M.G., K.H., and D.E. performed the experiments, K.M. and D.E. analyzed the data, and K.M. and D.E. wrote the manuscript. This study was supported by a grant to D.E. from the German Federal Ministry of Education and Research (BMBF) (01GQ0941) within the Bernstein Focus: Mechanisms of Learning and by a grant to D.E. from the Deutsche Forschungsgemeinschaft (DFG) within the research unit: Biogenic Amines in Insects (FOR1363).

We thank Joachim Haenicke, Martin Nawrot, Randolf Menzel, Julien Colomb, and Marco Schubert for fruitful discussions on the data and comments on earlier versions of the manuscript.

\section{References}

Annau Z, Kamin LJ. 1961. The conditioned emotional response as a function of intensity of the US. J Comp Physiol Psychol 54: 428-432.

Belelovsky K, Elkobi A, Kaphzan H, Nairn AC, Rosenblum K. 2005. A molecular switch for translational control in taste memory consolidation. Eur J Neurosci 22: 2560-2568.

Berridge KC. 2012. From prediction error to incentive salience: mesolimbic computation of reward motivation. Eur J Neurosci 35: 1124-1143.

Bitterman ME. 1996. Comparative analysis of learning in honeybees. Anim Learn Behav 24: 123-141.

Bitterman ME, Menzel R, Fietz A, Schafer S. 1983. Classical conditioning of proboscis extension in honeybees (Apis mellifera). J Comp Psychol 97: 107-119.

Buchanan GM, Bitterman ME. 1988. Learning in honeybees as a function of amount and frequency of reward. Anim Learn Behav 16: $247-255$.

Buchanan GM, Bitterman ME. 1989. Learning in honeybees as a function of amount of reward-tests of the equal-asymptote assumption. Anim Learn Behav 17: 475-480.

Burke CJ, Waddell S. 2011. Remembering nutrient quality of sugar in Drosophila. Curr Biol 21: 746-750.

Burke CJ, Huetteroth W, Owald D, Perisse E, Krashes MJ, Das G, Gohl D, Silies M, Certel S, Waddell S. 2012. Layered reward signalling through octopamine and dopamine in Drosophila. Nature 492: 433-437.

Chotiner JK, Khorasani H, Nairn AC, O'Dell TJ, Watson JB. 2003. Adenylyl cyclase-dependent form of chemical long-term potentiation triggers translational regulation at the elongation step. Neuroscience 116: $743-752$.

Couvillon PA, Bitterman ME. 1980. Some phenomena of associative learning in honeybees. J Comp Physiol Psychol 94: 578-885.

Couvillon PA, Bitterman ME. 1982. Compound conditioning in honeybees. J Comp Physiol Psychol 96: 192-199.

Couvillon PA, Bitterman ME. 1993. Learning in honeybees as a function of amount of reward-further experiments with color. Anim Learn Behav 21: $23-28$.

Couvillon PA, Lee YL, Bitterman ME. 1991. Learning in honeybees as a function of amount of reward-rejection of the equal-asymptote assumption. Anim Learn Behav 19: 381-387.

Davidkova G, Carroll RC. 2007. Characterization of the role of microtubule-associated protein $1 \mathrm{~B}$ in metabotropic glutamate receptor-mediated endocytosis of AMPA receptors in hippocampus. $J$ Neurosci 27: 13273-13278.

Davis RL. 2011. Traces of Drosophila memory. Neuron 70: 8-19.

Delamater AR. 2012. On the nature of CS and US representations in Pavlovian learning. Learn Behav 40: 1-23.

Delamater AR, Oakeshott S. 2007. Learning about multiple attributes of reward in Pavlovian conditioning. Ann N Y Acad Sci 1104: 1-20.

Federman N, Fustinana MS, Romano A. 2012. Reconsolidation involves histone acetylation depending on the strength of the memory. Neuroscience 219: 145-156.

Felsenberg J, Gehring KB, Antemann V, Eisenhardt D. 2011. Behavioural pharmacology in classical conditioning of the proboscis extension response in honeybees (Apis mellifera). J Vis Exp. doi: 10.3791/2282.

Friedrich A, Thomas U, Muller U. 2004. Learning at different satiation levels reveals parallel functions for the cAMP-protein kinase A cascade in formation of long-term memory. J Neurosci 24: 4460-4468.

Gil M. 2010. Reward expectations in honeybees. Commun Integr Biol 3: $95-100$.

Gil M, De Marco RJ. 2009. Honeybees learn the sign and magnitude of reward variations. J Exp Biol 212: 2830-2834.

Gil M, De Marco RJ, Menzel R. 2007. Learning reward expectations in honeybees. Learn Mem 14: 491-496.

Gil M, Menzel R, De Marco RJ. 2008. Does an insect's unconditioned response to sucrose reveal expectations of reward? PLoS One 3: e2810.

Gil M, Menzel R, De Marco RJ. 2009. Side-specific reward memories in honeybees. Learn Mem 16: 426-432.

Harris JA. 2011. The acquisition of conditioned responding. J Exp Psychol Anim Behav Process 37: 151-164.

Heise C, Gardoni F, Culotta L, di Luca M, Verpelli C, Sala C. 2014 Elongation factor-2 phosphorylation in dendrites and the regulation of dendritic mRNA translation in neurons. Front Cell Neurosci 8: 35. 
Im HI, Nakajima A, Gong B, Xiong X, Mamiya T, Gershon ES, Zhuo M, Tang YP. 2009. Post-training dephosphorylation of eEF-2 promotes protein synthesis for memory consolidation. PLoS One 4: e7424.

Jarome TJ, Kwapis JL, Werner CT, Parsons RG, Gafford GM, Helmstetter FJ. 2012. The timing of multiple retrieval events can alter GluR1 phosphorylation and the requirement for protein synthesis in fear memory reconsolidation. Learn Mem 19: 300-306.

Jimenez A, Carrasco L, Vazquez D. 1977. Enzymic and nonenzymic translocation by yeast polysomes. Site of action of a number of inhibitors. Biochemistry 16: 4727-4730.

Kim E, Graham LE. 2008. EEF2 analysis challenges the monophyly of Archaeplastida and Chromalveolata. PLoS One 3: e2621.

Kirkpatrick K. 2014. Interactions of timing and prediction error learning. Behav Processes 101: 135-145.

Lunney GH. 1970. Using analysis of variance with a dichotomous dependent variable: an empirical study. J Educ Meas 7: 263-269.

Madjar JJ, Nielsen-Smith K, Frahm M, Roufa DJ. 1982. Emetine resistance in chinese hamster ovary cells is associated with an altered ribosomal protein S14 mRNA. Proc Natl Acad Sci 79: 1003-1007.

Marin P, Nastiuk KL, Daniel N, Girault JA, Czernik AJ, Glowinski J, Nairn AC, Premont J. 1997. Glutamate-dependent phosphorylation of elongation factor- 2 and inhibition of protein synthesis in neurons. J Neurosci 17: 3445-3454.

Matsumoto Y, Sandoz JC, Devaud JM, Lormant F, Mizunami M, Giurfa M. 2014. Cyclic nucleotide-gated channels, calmodulin, adenylyl cyclase, and calcium/calmodulin-dependent protein kinase II are required for late, but not early, long-term memory formation in the honeybee. Learn Mem 21: 272-286.

Menzel R. 1968. On honey bees memory of spectral colours. I. Long-term and short-term retention. Z Vgl Physiol 60: 82-102.

Menzel R. 1990. Learning, memory, and "cognition" in honey bees. In Neurobiology of comparative cognition (ed. Kesner RP, Olton DS), pp. 237-292. Lawrence Erlbaum Associate, Hillsdale, NJ.

Menzel R. 1999. Memory dynamics in the honeybee. J Comp Physiol A 185: 323-340.

Menzel R. 2001. Searching for the memory trace in a mini-brain, the honeybee. Learn Mem 8: 53-62.

Menzel R, Erber J. 1972. The influence of the quantity of reward on learning performance in honeybees. Behaviour 41: 27-42.

Menzel R, Greggers U, Hammer M. 1993. Functional organization of appetitive learning and memory in a generalist pollinator, the honey bee. In Insect learning: ecological and evolutionary perspectives (ed. Papaj DR, Lewis AC), pp. 79-125. Chapman \& Hall, New York.

Menzel R, Manz G, Greggers U. 2001. Massed and spaced learning in honeybees: the role of CS, US, the intertrial interval, and the test interval. Learn Mem 8: 198-208.

Opfinger E. 1931. Über die Orientierung der Biene an der Futterquelle. J Comp Physiol A Neuroethol Sens Neural Behav Physiol 15: 431-487.

Park S, Park JM, Kim S, Kim JA, Shepherd JD, Smith-Hicks CL, Chowdhury S, Kaufmann W, Kuhl D, Ryazanov AG, et al. 2008. Elongation factor 2 and fragile X mental retardation protein control the dynamic translation of Arc/Arg3.1 essential for mGluR-LTD. Neuron 59: $70-83$.

Rehder V. 1987. Quantification of the honeybee's proboscis reflex by electromyographic recordings. J Insect Physiol 33: 7.

Rescorla RA, Wagner AR. 1972. A theory of Pavlovian conditioning: variations in the effectiveness of reinforcement and nonreinforcement.
In Classical conditioning II: current theory and research (ed. Black AH, Prokasy WF), pp. 64-99. Appleton-Century-Crofts, New York. Ryazanov AG, Shestakova EA, Natapov PG. 1988. Phosphorylation of elongation factor 2 by EF-2 kinase affects rate of translation. Nature 334: $170-173$.

Sandoz JC, Hammer M, Menzel R. 2002. Side-specificity of olfactory learning in the honeybee: US input side. Learn Mem 9: 337-348.

Scheetz AJ, Nairn AC, Constantine-Paton M. 2000. NMDA receptormediated control of protein synthesis at developing synapses. Nat Neurosci 3: 211-216.

Schmidt EK, Clavarino G, Ceppi M, Pierre P. 2009. SUnSET, a nonradioactive method to monitor protein synthesis. Nat Methods 6: 275-277.

Schultz W. 2007. Behavioral dopamine signals. Trends Neurosci 30: 203-210.

Schultz W, Dayan P, Montague PR. 1997. A neural substrate of prediction and reward. Science 275: 1593-1599.

Seeley TD. 1995. The wisdom of the hive: the social physiology of honey bee colonies. Harvard University Press, Cambridge, MA.

Shafir S, Yehonatan L. 2014. Comparative evaluations of reward dimensions in honey bees: evidence from two-alternative forced choice proboscis-extension conditioning. Anim Cogn 17: 633-644.

Smith BH, Menzel R. 1989a. An analysis of variability in the feeding motor program of the honey bee-the role of learning in releasing a modal action pattern. Ethology 82: 68-81.

Smith BH, Menzel R. 1989b. The use of electromyogram recordings to quantify odorant discrimination in the honey bee, Apis mellifera. J Insect Physiol 35: 369-375.

Smith KS, Berridge KC, Aldridge JW. 2011. Disentangling pleasure from incentive salience and learning signals in brain reward circuitry. Proc Natl Acad Sci 108: E255-E264.

Snodgrass RE. 1956. The Thorax. In Anatomy of the honeybee. New York.

Stollhoff N, Eisenhardt D. 2009. Consolidation of an extinction memory depends on the unconditioned stimulus magnitude previously experienced during training. J Neurosci 29: 9644-9650.

Tully T, Quinn WG. 1985. Classical-conditioning and retention in normal and mutant Drosophila melanogaster. J Comp Physiol A 157: 263-277.

Tully T, Preat T, Boynton SC, Del Vecchio M. 1994. Genetic dissection of consolidated memory in Drosophila. Cell 79: 35-47.

Von Frisch K. 1967. The dance language and orientation of bees. The Belknap Press of Harvard University Press, Cambridge, MA.

Wong W, Bai XC, Brown A, Fernandez IS, Hanssen E, Condron M, Tan YH, Baum J, Scheres SH. 2014. Cryo-EM structure of the Plasmodium falciparum $80 \mathrm{~S}$ ribosome bound to the anti-protozoan drug emetine. eLife: e03080.

Wright GA, Mustard JA, Kottcamp SM, Smith BH. 2007. Olfactory memory formation and the influence of reward pathway during appetitive learning by honey bees. J Exp Biol 210: 4024-4033.

Wustenberg D, Gerber B, Menzel R. 1998. Short communication: long- but not medium-term retention of olfactory memories in honeybees is impaired by actinomycin D and anisomycin. Eur J Neurosci 10: $2742-2745$.

Received April 29, 2014; accepted in revised form September 5, 2014. 

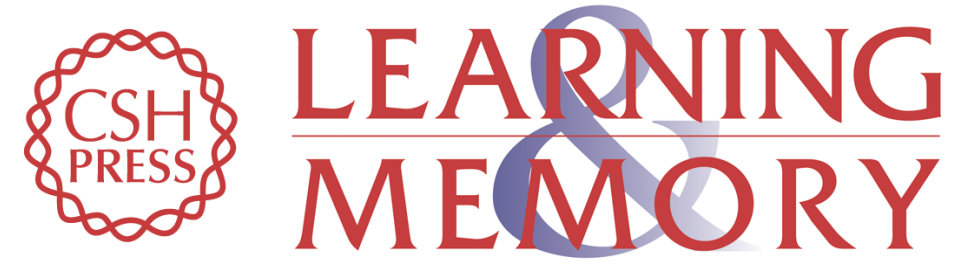

\section{Duration of the unconditioned stimulus in appetitive conditioning of honeybees differentially impacts learning, long-term memory strength, and the underlying protein synthesis}

Kathrin Marter, M. Katharina Grauel, Carmen Lewa, et al.

Learn. Mem. 2014, 21:

Access the most recent version at doi:10.1101//m.035600.114

References This article cites 60 articles, 16 of which can be accessed free at: http://learnmem.cshlp.org/content/21/12/676.full.html\#ref-list-1

Creative This article is distributed exclusively by Cold Spring Harbor Laboratory Press for the Commons first 12 months after the full-issue publication date (see

License http://learnmem.cshlp.org/site/misc/terms.xhtml). After 12 months, it is available under a Creative Commons License (Attribution-NonCommercial 4.0 International), as described at http://creativecommons.org/licenses/by-nc/4.0/.

Email Alerting Receive free email alerts when new articles cite this article - sign up in the box at the Service top right corner of the article or click here. 